\title{
Anti-Phospholipid Antibody Syndrome with Subdural Hematoma: A Case Report
}

Uddin $\mathrm{MN}^{1}$, Karim $\mathrm{AKMB}^{2}$, Akter $\mathrm{N}^{3}$, Ahmed $\mathrm{M}^{4}$, Orin $\mathrm{M}^{5}$, Tanni $\mathrm{SA}^{6}$, Asaduzzaman $\mathrm{M}^{7}$, Joarder $\mathrm{MA}^{8}$, Saleh $\mathrm{AJM}^{9}$, Ahsan $\mathrm{S}^{10}$, Jahangir $\mathrm{SM}^{11}$, Chandy $\mathrm{MJ}^{12}$

\begin{abstract}
A 33-year-old man with anti-phospholipid antibody syndrome associated with Budd Chiari syndrome and subdural hematoma. He developed venous thrombosis in his hepatic vein (stenting done) when laboratory studies demonstrated prolongation of activated partial thromboplastin time (APTT). Subdural hematoma demonstrated with Computed tomography (CT) of brain. Laboratory studies revealed thrombocytopenia, prolonged bleeding time and APTT, positive antinuclear antibody and positive test results for both lupus anticoagulant and an anti-cardiolipin antibody, namely antiphospholipid antibodies. Based on these findings, we consider that the tendency of this bleeding may have been due to antiphospholipid antibodies, attacking the platelet membranes and that the bridging veins in the subdural space may be the site at which the bleeding tendency easily appears. Antiphospholipid antibody syndrome accompanied by hemorrhagic complications had rarely been reported. We suggest that special attention should be given to hemorrhagic complications in patients with antiphospholipid antibody syndrome associated with fragility of the vessels and/or platelet dysfunction and on anticoagulant (warfarin).
\end{abstract}

\section{Keywords}

Antiphospholipid antibody syndrome, Anticardiolipin antibody syndrome, Subdural hematoma, Budd Chiari syndromes

\section{Introduction}

Antiphospholipid antibody syndrome (APS) also known as anticardiolipin antibody syndrome, lupus anticoagulant syndrome, or Hughes syndrome was first described by Hughes et $\mathrm{al}^{1}$ as a condition characterized by propensity for arterial/venous thrombosis, recurrent fetal wastage and thrombocytopenia. The presence of an antiphospholipid antibody can be documented by a solid phase serum assay of anticardiolipin, or an inhibitor of phospholipid-dependent clotting (lupus anticoagulant) or both. ${ }^{2}$

APS can occur as an isolated diagnosis, known as primary antiphospholipid antibody syndrome or can be associated with systemic lupus erythematosus (SLE) or other rheumatic diseases when

1. Clinical Associate, Dept. of Neurosurgery, Apollo Hospitals Dhaka 2. Specialist, Dept. of Neurosurgery, Apollo Hospitals Dhaka 3. Clinical Associate, Dept. of Neurosurgery, Apollo Hospitals Dhaka 4. Resident Medical Officer, Dept. of Neurosurgery, Apollo Hospitals Dhaka 5. Resident Medical Officer, Dept. of Neurosurgery, Apollo Hospitals Dhaka 6. Resident Medical Officer, Dept. of Neurosurgery, Apollo Hospitals Dhaka 7. Resident Medical Officer, Dept. of Neurosurgery, Apollo Hospitals Dhaka 8. Consultant, Dept. of Neurosurgery, Apollo Hospitals Dhaka 9. Consultant \& Coordinator, Dept. of Adult Hematology / HSCT, Apollo Hospitals Dhaka 10. Consultant, Dept. of Radiology \& Imaging, Apollo Hospitals Dhaka 11. Sr. Consultant \& Coordinator, Dept. of Anaesthesia \& Critical Care (Neuro Science), Apollo Hospitals Dhaka 12. Sr. Consultant \& Coordinator, Dept. of Neurosurgery, Apollo Hospitals Dhaka 
when it is known as secondary APS. ${ }^{3}$ Even though APS is a condition commonly associated with arterial or venous thrombosis, very rarely it can lead on to hemorrhage also. ${ }^{4}$ This occurs when patients with APS develop antibodies directed against prothrombin leading on to clinically significant hypoprothrombinemia leading to hemorrhage. There are only very few case reports of lupus anticoagulant- hypoprothrombinemia syndromes. Spontaneous subdural hematoma is unusual and difficult to treat. Herein, we report a case of Budd Chiari syndromes secondary to APS who presented with subdural hematoma.

\section{Case report}

A 33 years old male presented to us with the history of sudden severe headache and nausea for 3 weeks. He had history of admission under gastroenterology due to oral bleeding, oral ulcer and severe headache 3 weeks back. He was diagnosed to have grade II/III oesophageal varices which was treated by endoscopic variceal Ligation (EVL) and bilateral subdural hematoma which was treated conservatively. He was known case of antiphospholipid antibody syndrome with Budd Chiari Syndrome, stenting of hepatic venous thrombosis done on July 2015 and was on anticoagulant warfarin. His INR at the time of the episode of subdural hematoma was 12 and he was receiving warfarin $5 \mathrm{mg}$ daily. Computed tomography (CT) and CT angiography showed bilateral chronic subdural hematoma (left >right) (Fig. 1). Other investigations revealed thrombocytopenia ( 60 $10^{\wedge} 9 / \mathrm{L}$ ), prolonged bleeding time (12 minutes, reference range 2-7 minutes) and prolong APTT (50 secs, reference range $25-31.3 \mathrm{sec}$ ), positive antinuclear antibody and positive test results for both lupus anticoagulant (2.49, Reference range $<1.20)$ and an anticardiolipin antibody (15.28 $\mathrm{U} / \mathrm{ml}$, Cut off value - $10 \mathrm{U} / \mathrm{ml}$ ).

A diagnosis of Budd Chiari Syndrome secondary to antiphospholipid antibody syndrome with subdural hematoma (left > right) was made. We treated him by surgical intervention burr hole and evacuation of hematoma with precaution by involving hematology and gastroenterology department. We prepared him by holding oral anticoagulant, transfusion of apheresis platelet for thrombocytopenia and fresh frozen plasma (FFP) to correct APTT. Anticoagulant was resumed from the second postoperative day in the form of low molecular weight heparin with close monitoring for bleeding. Anticoagulant was shifted to oral form with rivaroxaban instead of warfarin from 10th POD onwards. A repeat CT Scan of brain was carried out (Fig. 2). Presently, he is maintaining his INR around 1.5-2 for last 4 months without further episodes of thrombosis or bleeding.

\section{Discussion}

APS is a syndrome complex characterized by recurrent venous/arterial thrombosis, obstetrical complications like recurrent fetal loss, intrauterine growth retardation, and thrombocytopenia. It can occur as a primary disease without any underlying connective tissue disease when it is known as primary APS, and also as a complica- 


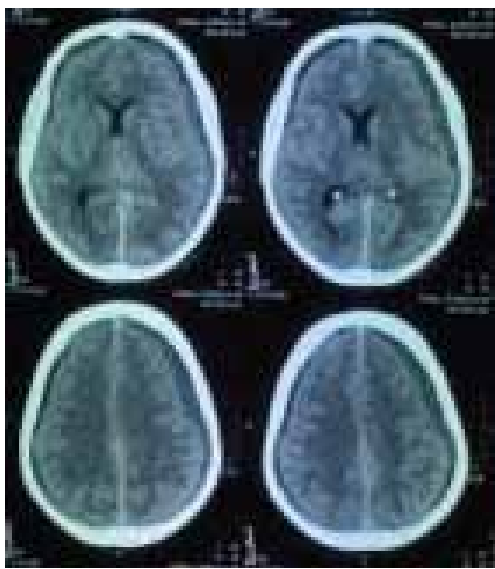

Fig. 1: Preoperative CT scan

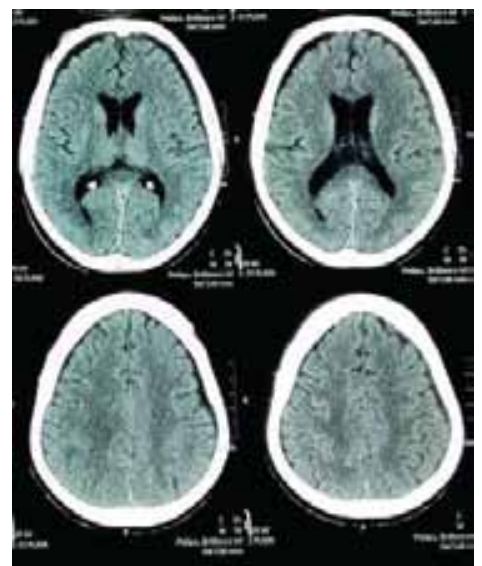

Fig. 2: Postoperative CT scan also as a complication secondary to SLE or lupus like syndromes.

Our patient had history of positive lupus anticoagulant and anticardiolipin antibodies. This patient also had prolonged APTT, high International normalize ratio (INR) and low platelet count. These features suggest that the patient had associated secondary APS also.

Antiphospholipid antibody syndrome (APS) is one of the major causes of acquired thrombophilia, in which venous or arterial thrombosis, or both, may occur. But patients with the lupus anticoagulant directed against prothrombin, on rare occasions, may develop clinically important hypoprothrombinemia leading to hemorrhage. This is a very rare complication of APS and has previously been reported to occur more often in children. ${ }^{5}$ The high rate of recurrence of thrombosis suggests that these patients require longterm anticoagulation. Prospective studies have shown that treatment with warfarin is highly effective in preventing recurrent thrombosis as compared to aspirin. However, there is still no consensus about the duration and dosage of prophylactic antithrombotic therapy. Studies suggest that oral anticoagulation should be maintained long term and the International Normalized Ratios (INR) should be around 3 in patients who have experienced previous thrombotic events. High intensity anticoagulation (INR >3) was associated with $90 \%$ probability of a five-year thrombosisfree follow up. ${ }^{6}$ However, the benefits of longterm and high intensity anticoagulation should be weighed against the risks of bleeding. Hart et al suggested that intracranial haemorrhage is the most common, feared, and frequently lethal complication of oral anticoagulation. ${ }^{7}$ Age (older than 65), uncontrolled hypertension, combination of warfarin and aspirin, drug interaction between azathioprine and warfarin, and concomitant administration of oral anticoagulants and methylprednisolone have been identified as risk factors for bleeding in patients with APS. ${ }^{8}$

Our patient was young and did not have any of 
these risk factors for subdural hematoma but there was omission in monitoring of anticoagulation for more than a month, leading to an undetected increase in INR.

Fihn ${ }^{9}$ has suggested that the risk of major bleeding in patients receiving oral anticoagulation is cumulative, with more than $20 \%$ of patients experiencing major bleeding episodes within the first four years of treatment. An INR $>3$ has been recommended in patients with $\mathrm{APS}^{2}$. However, it has been reported that each increase of 1 in the INR is associated with a $42 \%$ increase in major bleeding episodes 11 and that the risk of intracranial haemorrhage markedly increases with an INR between 3.7 and $4.05 .{ }^{10}$ The rate of life threatening bleeding in subjects taking warfarin, based on a prospective study is at least $0.25 \%$ a year. ${ }^{11}$ In APS, serious bleeding complications may occur, but their risk is not higher than that found in other thrombotic conditions warranting oral anticoagulation. ${ }^{12}$

Our case exemplifies that prolonged and regular monitoring of INR in patients on long-term oral anticoagulation is essential. Even if a constant dose of oral anticoagulant is being administered, monitoring of INR is crucial. The treating physician and the patient need to be aware of the risk of major bleeding with the inherent risk of mortality.

\section{Conclusion}

We suggest that special attention should be given to hemorrhagic complications in patients with anti-phospholipid antibody syndrome associated with fragility of the vessels and/or platelet dysfunction and on anticoagulant (warfarin).

\section{Reference}

1. Hughes GR. Thrombosis, abortion, cerebral disease and lupus anticoagulant. Br Med J, 1983; 287(6399): 1088-9.

2 . Hughes GRV. The Antiphospholipid antibody syndrome: ten years on. Lancet, 1993; 342: 341-4.

3. Bick RL, Baker WF. The Antiphospholipid and thrombosis syndromes. Med Clin North Am, 1994; 78: 667-84.

4. Erkan D, Bateman H, Lockshin MD. Lupus anticoagulant hypoprothrombinemia syndrome associated with SLE: report of two cases and review of literature. Lupus, 1999; 8(7): $560-4$.

5. Becton DL, Stine KC. Transient lupus anticoagulants associated with hemorrhage rather than thrombosis: the hemorrhagic lupus anticoagulant syndrome. J Pediatr, 1997; 130: 998-1000.

6. Khamashta MA, Cuadrado MJ, Mujic F, Taub NA, Hunt BJ, Hughes GR. The management of thrombosis in the antiphospholipid antibody syndrome. N Engl J Med, 1995; 332(15):993-7.

7. Hart RG, Boop BS, Anderson DC. Oral anticoagulants and intracranial haemorrhage. Facts and hypotheses. Stroke, 1995; 26(8):1471-7.

8. Castellino G, Cuadrado MJ, Godfrey T, Khamashta MA, Hughes GRV. Characteristics of patients with antiphospholipid syndrome with major bleeding after oral antico- agulant treatment. Ann Rheum Dis, 2001; 60(5):527-30.

9. Fihn SD, McDonell M, Martin D, Henikoff J, Vermes D, Kent D, et al. Risk factors for complications of chronic anticoagulation. Ann Intern Med, 1993; 118:511-20.

10. Hylek EM, Singer DE. Risk factors for intracranial hemorrhage in outpatients taking warfarin. Ann Intern Med, 1994; 120(11):897-902.

11. Palareti G, Leali N, Coccheri S, Poggi M, Manotti C, D'Angelo A, et al. Bleeding complications of oral anticoagulant therapy. Lancet, 1996; 348(9025):423-8

12. Al-Sayeh FA, Ensworth S, Huang S, Stein H, Kinkho V. Hemorrhagic complications of longterm anticoagulant therapy in 7 patients with SLE and antiphospholipid syndrome. J Rheumatol, 1997; 24:1716-18. 